\title{
PERANCANGAN APLIKASI M-LEARNING UNTUK PEMBELAJARAN E- BUSINESS BAGI MAHASISWA DENGAN MENGGUNAKAN PERANGKAT MOBILE BERBASIS ANDROID
}

\author{
Harkamsyah Andrianof, M.Kom \\ Fakultas Ilmu Komputer, Universitas Putra Indonesia YPTK Padang \\ harkamsyah.andrianof@upiyptk.ac.id
}

\begin{abstract}
In supporting the success and smoothness the process of learning, the thing that must be considered is learning resources. With the fast development of technology at the moment, the learning resources are not limited to conventional media such as text books. The content that comes from books currently has been transformed into digital form with more effective and efficient learning models, such as Mobile learning. In this case, the author is motivated to develop a software that functions as a learning medium by utilizing the benefits of a mobile smartphone based on the Android operating system. This software can be a learning media that make it easy to learn e-business science with priority material about e-business infrastructure. This application has the aim to assist teachers in delivering material outside of lecture hours, making it easier for students to learn through smartphones that can increase student interest in learning.
\end{abstract}

Keywords $\quad$ : Mobile, Learning, Android, E-Bussines

\begin{abstract}
Abstrak
Dalam mendukung sukses dan lancarnya suatu proses belajar, hal yang harus diperhatikan adalah sumber belajar. Dengan pesatnya perkembangan teknologi pada saat ini, sumber belajar yang tersedia sangat tidak terbatas hanya pada media konvensional seperti buku-buku cetak. Konten-konten yang berasal dari buku-buku saat ini telah banyak ditransformasikan kedalam bentuk digital dengan model pembelajaran yang lebih efektif dan efisien, seperti Mobile learning. Dalam hal ini, penulis termotivasi untuk mengembangkan sebuah perangkat lunak yang berfungsi sebagai media belajar dengan memanfaatkan kelebihan perangkat mobile smartphone berbasis sistem operasi android. Perangkat lunak ini dapat menjadi sebuah media pembelajaran yang memberi kemudahan belajar ilmu e-business dengan prioritas materi tentang infrastruktur e-business. Aplikasi ini memiliki tujuan untuk membantu pengajar dalam menyampaikan materi di luar jam perkuliah, mempermudah mahasiswa belajar melalui smartphone yang dimiliki sehingga dapat menambah minat belajar mahasiswa.
\end{abstract}

Kata Kunci : Mobile, Learning, Android, E-Bussines

1. PENDAhUluan

Kemajuan teknologi merupakan suatu hal yang sangat bagus dalam kehidupan saat ini, sebab dengan adanya perkembangan teknologi menjadikan segala pekerjaan menjadi lebih mudah dan lebih cepat. Pada dasarnya teknologi membawa implikasi positif dalam sejarah kehidupan manusia dalam proses belajar mengajar. Untuk mendukung lancar dan suksesnya proses belajar hal yang harus diperhatikan adalah sumber belajar. Pada proses 
pembelajaran pada era berkembangnya ini, tidak hanya berpaku pada buku-buku yang dianggap sudah lama dan terkadang sulit untuk dipahami. Terciptanya alat komunikasi akan menyebabkan proses belajar menjadi lebih nyaman, cepat dan menyenangkan serta efisien seperti e-learning. E-learning merupakan model pembelajaran dengan memanfaatkan media elektronik dan teknologi informasi berbasis komputer dan internet.

Berdasarkan hal diatas penulis termotivasi untuk mengembangkan sebuah perangkat lunak yang berfungsi sebagai media belajar dengan memanfaatkan kelebihan perangkat mobile smartphone berbasis sistem operasi android.

Dengan demikian penulis memutuskan menggunakan judul sebagai berikut " PERANCANGAN APLIKASI M-LEARNING UNTUK PEMBELAJARAN EBUSINESS BAGI MAHASISWA DENGAN MENGGUNAKAN PERANGKAT MOBILE BERBASIS ANDROID".

\section{Adapun Tujuan dan manfaat dari penelitian ini adalah sebagai berikut :}

1) Memanfaatkan kemajuan teknologi untuk menciptakan aplikasi yang memberikan kemudahan belajar.

2) Dengan adanya aplikasi ini diharapkan mampu membantu proses belajar pengguna sehingga meningkatkan pemahamanan materi tentang ebusiness.

\section{Metode Penelitian}

Dalam penelitian ini penulis memerlukan beberapa data mengenai objek penelitian. Adapun teknik pengumpulan data dalam penelitian ini dilakukan dengan cara sebagai berikut:

1) Penelitian Lapangan (Field Research)

2) Penelitian Kepustakaan (Library Research)

3) Penelitian Laboratorium (Laboratory Research)

\section{METODE PENELITIAN 2.1 Mobile Learning}

Istilah mobile learning (m-learning) mengacu kepada penggunaan perangkat IT genggam dan bergerak, seperti PDA, telepon genggam, laptop dan tablet PC, dalam pengajaran dan pembelajaran. M-learning merupakan suatu pembelajara yang unik. Hal ini dikarenakan pembelajar dapat mengakses materi pembelajaran, dengan menggunakan arahan dan aplikasi yang berkaitan dengan course kapanpun dan dimana-pun. Hal ini dapat meningkatkan perhatian pada materi pembelajaran, membuat pembelajaran menjadi pervasif, dan dapat mendorong motivasi pembelajar kepada pembelajaran sepanjang hayat (lifelong learning).

Mobile learning atau m-learning sering didefinisikan sebagai e-learning melalui perangkat komputasi mobile yang mana merupakan penyampaian bahan pembelajaran elektronik pada alat komputasi mobile agar dapat diakses dari mana saja dan kapan saja.)

\subsubsection{Klasifikasi Mobile Learning} Proses pembelajaran M-Learning dapat dikelompokkan dalam beberapa 
klasifikasi tergantung dari beberapa sudut pandang. Dari sisi teknologi ICT yang digunakan, maka M-Learning dapat diklasifikasi berdasar indikator utama:

Dari sudut pandang teknologi pengajaran maka m-learning dapat diklasifikasikan berdasar indikator berikut: Mendukung pembelajaran asynchronous dan atau synchronous;

1. Mendukung e-learning standar.

2. Ketersediaan koneksi internet permanen antara sistem dan pengguna.

3. Lokasi pengguna.

4. Layanan akses ke materi pembelajaran dan/atau administrasi.

\subsection{Konsep E-Business}

Aplikasi e-Business merupakan sebuah kegiatan bisnis yang secara otomatis dan semi otomatis dilakukan dengan menggunakan teknologi elektronik. EBusiness memungkinkan suatu perusahaan untuk berhubungan dengan sistem pemprosesan data internal dan eksternal. EBusiness juga banyak dipakai untuk berhubungan dengan suplier dan mitra bisnis perusahaan, serta memenuhi permintaan dan melayani kepuasan pelanggan secara lebih baik.

\subsubsection{Keuntungan E- Business}

Ada beberapa keuntungan e-Business yang diperoleh oleh perusahaan, yaitu :

a. Revenue stream (aliran pendapatan) baru yang mungkin lebih menjanjikan yang tidak bisa ditemui di sistem transaksi tradisional.

b. Dapat meningkatkan sebuah market exposure (pangsa pasar)

c. Menurunkan biaya operasional (operating cost)

d. Melebarkan jangkauan (global reach)

e. Meningkatkan customer loyality

f. Meningkatkan supplier management g. Memperpendek waktu produksi

h. Meningkatkan value chain (mata rantai pendapatan).

\subsubsection{Contoh Aplikasi E- Business}

Aplikasi e-business dalam sebuah proses komunikasi dan kolaborasi perusahaan digunakan untuk mendukung komunikasi bisnis, koordinasi dan kolaborasi oleh anggota tim bisnis dalam perusahaan tersebut. Aplikasi e-Business yang digunakan meliputi:

1. Surat elektronik (e-mail)

2. Surat bersuara (voice mail)

3. Forum diskusi

4. Sistem percakapan tertulis (chatting)

5. Konferensi suara

6. Konverensi video

\subsection{Software Untuk Membangun Aplikasi} 2.3.1 Adobe Flash CS6

Adobe Flash CS6 adalah salah satu perangkat lunak komputer yang merupakan produk unggulan adobe systems. Adobe Flash CS6 digunakan untuk membuat gambar vector maupun animasi gambar tersebut. Berkas yang dihasilkan dari perangkat lunak ini mempunyai file extension.

\subsubsection{Fitur Pada Adobe Flash CS6}

Berikut ini beberapa fitur yang ada pada adobe flash CS6: (Sumber: Wahana Komputer, 2012)

a. Memberikan dukungan untuk HTML 5.

b. Ekspor simbol dan urutan animasi yang cepat menghasilkan sprite sheet untuk meningkatkan pengalaman gaming, alur kerja, dan perfomance.

c. Memberikan dukungan untuk Android dan iOS dengan Adobe Flash player terbaru. 
d. Performanya memberikan pemuatan foto berukuran besar menjadi lebih cepat. Hal ini terwujud berkat adanya Adobe Mercury Graphics Engine yang mampu meminimalisir waktu render.

\subsubsection{Membuat Objek}

Tampilan objek pada Adobe Flash dapat dibagi menjadi dua, yakni objek yang dibuat pada program flash dan objek yang di impor ke dalam flash. Teknik pembuatan objek dengan program Adobe Flash berbeda dengan pembuatan objek pada programprogram desain grafis. Perbedaanya terletak pada karakteristik objek yang dibuat. (Sumber: Wahana Komputer, 2012)

\subsubsection{Mempublikasikan Dokumen}

Project yang telah dibuat pada flash selanjutnya dapat kita publikasikan dan dijalankan dengan program aplikasi lainnya. Ini berarti proyek yang dipublikasikan tidak perlu dibuka atau dijalankan dengan menggunakan program flash lagi.

Beberapa format hasil publikasi yang disediakan oleh flash diantaranya adalah SWF, HTML, GIF, PNG, dan JPEG

\section{HASIL DAN PEMBAHASAN \\ 3.1 Analisa Sistem}

Analisis sistem dilakukan setelah tahap investigasi sistem dan sebelum tahap rancangan sistem. Tahap analisis sistem merupakan tahap yang kritis dan sangat penting, karena kesalahan ditahap ini akan menyebabkan kesalahan pada tahap selanjutnya.

Adapun tujuan utama dari tahap analisis sistem ini adalah.

1. Memberikan pelayanan kebutuhan informasi

2. Membuat para pengambil keputusan,
3. Mengevaluasi sistem-sistem yang telah ada dan berjalan sampai saat ini

4. Merumuskan tujuan-tujuan yang ingin dicapai

5. Menyusun suatu tahap rencana pengembangan sistem dan penerapannya

\subsubsection{Analisa sistem yang sedang berjalan} Adapun sistem yang saat ini sedang berjalan yaitu :

1) Pembelajaran E- Bussines di lakukan dikelas pada waktu tertentu

2) Pembelajaran dilakukan dengan tatap muka langsung antara dosen dan mahasiswa.

3) Dosen menyampaikan materi pembelajaran dan mahasiswa mencatat materi yang disampaikan oleh dosen ke dalam buku catatan masing-masing.

4) Jika masih ada waktu dosen akan memberikan soal latihan kepada mahasiswa

\subsubsection{Usulan sistem baru}

Untuk mengatasi masalah-masalah yang terdapat pada sistem yang sedang berjalan, maka penulis akan merancang suatu aplikasi pembelajaran berbasis mobile sehingga dapat membantu dosen menyampaikan materi di luar jam kuliah

\subsection{UML(Unified Modelling Language)}

UML (Unified Modelling Language) adalah salah satu alat bantu yang sangat handal didunia pengembangan system yang berorientasi obyek.

\subsubsection{Diagram Use Case}

Pada diagram use case, digambarkan fungsifungsi apa saja yang ada di dalam aplikasi mobile learning pembelajaran E-business. 
Use Case Diagram dari perancangan aplikasi M-Learning dapat dilihat pada gambar 3.1 :

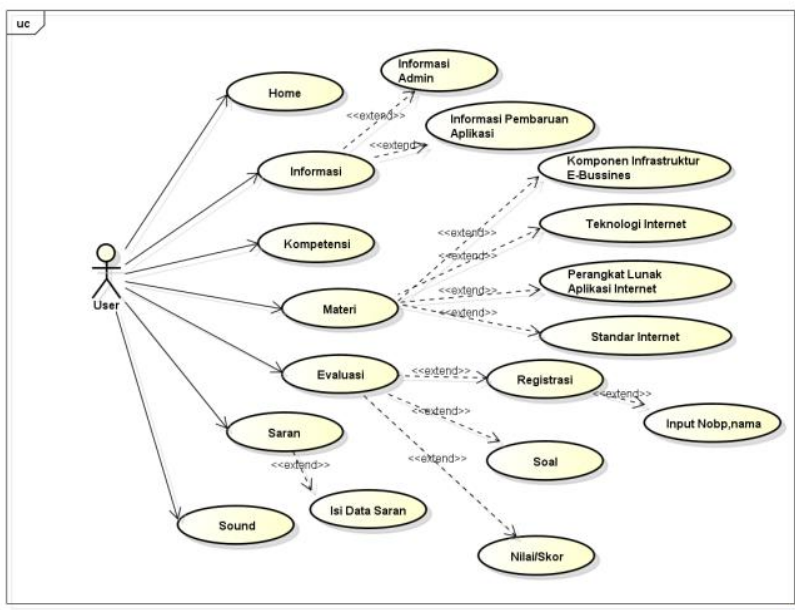

Gambar 3.1 Use Case Diagram

\subsubsection{Class Diagram}

Diagram kelas atau class diagram menggambarkan kumpulan kelas-kelas objek. Pada diagram kelas ini akan dijelaskan tentang kelas-kelas yang terdapat pada aplikasi mobile learning.

Diagram kelas dapat dilihat pada gambar 3.2 berikut ini :

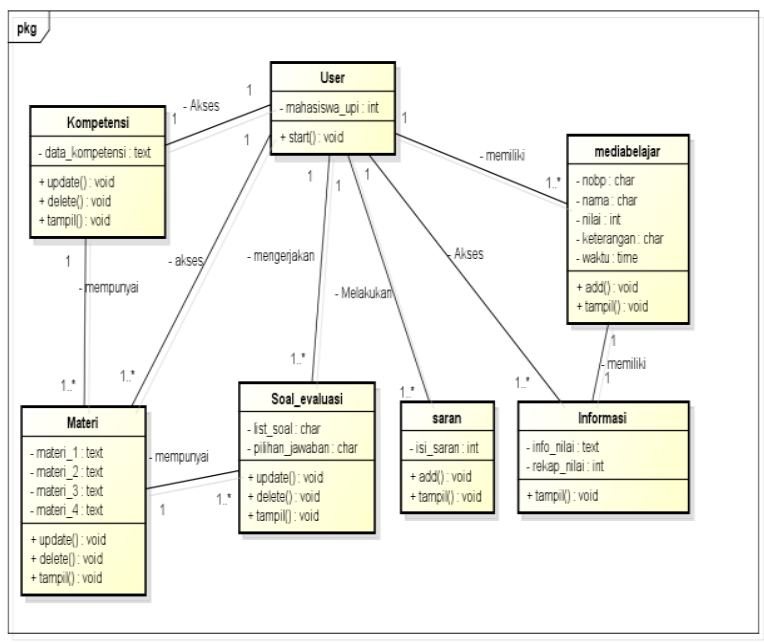

Gambar 3.2 Class Diagram

\subsubsection{Activity Diagram}

Activity Diagram menggambarkan aliran aktifitas-aktifitas yang dapat dilakukan oleh user yang melalui program

Gambar activity diagram user dapat dilihat pada gambar 3.3 berikut ini :

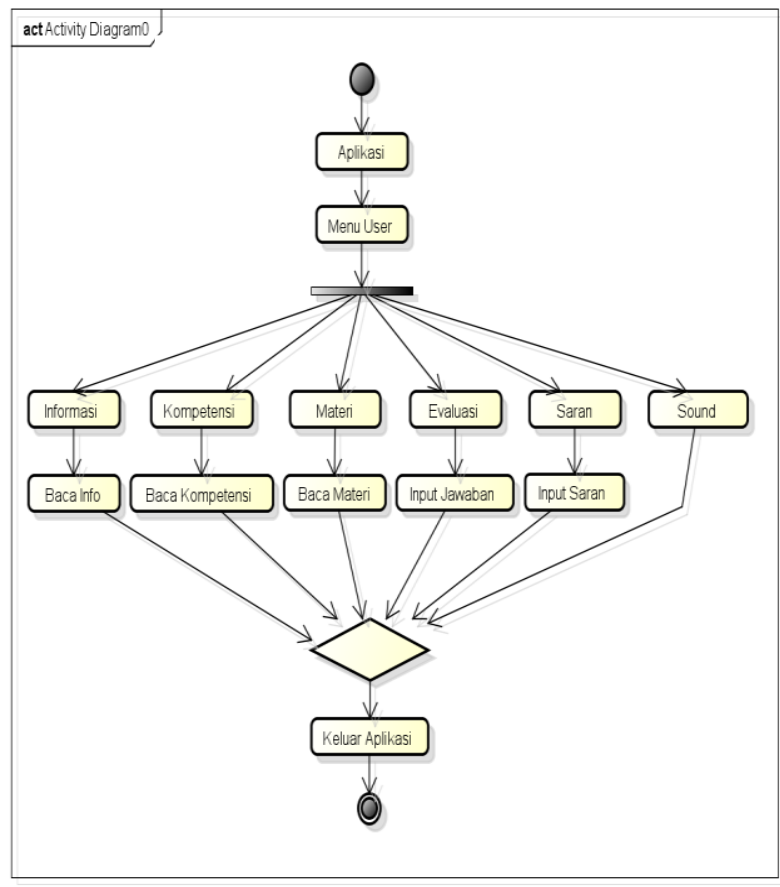

Gambar 3.3 Activity diagram User

\subsubsection{Sequence Diagram}

Sequence diagram menjelaskan interaksi objek yang disusun dalam urutan waktu. Yaitu sequence menu diagram menu home, diagram menu informasi, diagram menu kompetensi, diagram menu materi, diagram menu evaluasidan diagram menu saran.

\subsubsection{Deployment Diagram}

diagram ini menunjukkan konfigurasi komponen dalam proses eksekusi aplikasi. Aplikasi mobile learning ini dibangun untuk dapat diakses melalui aplikasi mobile

Diagram deployment aplikasi mobile learning untuk pembelajaran komputer dan masyarakat dapat dilihat pada gambar 3.10 berikut ini : 


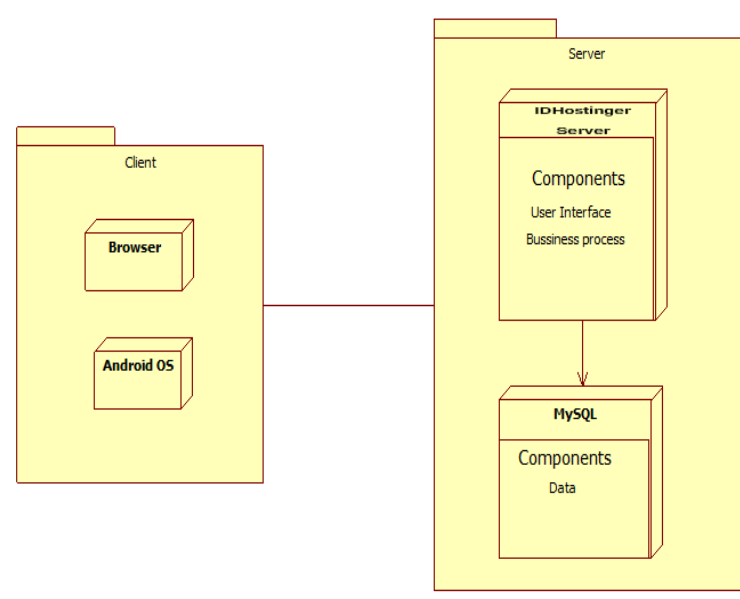

Gambar Deployment diagram system

\section{KESIMPULAN}

Dari pembahasan dan hasil analisa yang dilakukan sampai terbentuknya rancangan aplikasi publikasi mobile learning , maka penulis menarik kesimpulan sebagai berikut :

1) Penulis berhasil merancang dan mengimplementasikan suatu aplikasi mobile learning pada perangkat mobile berbasis Android.

2) Aplikasi mobile learning ini dapat digunakan untuk pembelajaran materi e-business.

3) Aplikasi mobile learning menggunakan animasi 2 dimensi (gambar bergerak) untuk menambah daya tarik pengguna aplikasi untuk belajar.

4) Aplikasi mobile learning tentang pembelajaran e-business dapat diakses dengan perangkat mobile berbasis android milik pengguna, sehingga pengguna dapat belajar dimana saja dan kapan saja dengan menggunakan perangkat mobile.

5) Dengan adanya aplikasi mobile learning tentang pembelajaran ebusiness, pengguna dapat meningkatkan pemahaman dengan mengerjakan soal latihan dan evaluasi yang disediakan oleh aplikasi.

\section{UCAPAN TERIMAKASIH}

1) Pada kesempatan kali ini, penulis sangat berterima kasih kepada rekan-rekan yang terkait dalam pembuatan jurnal ini, sehingga menghasilkan aplikasi yang bermanfaat bagi kedepannya

2) Tak luput ucapan terimakasib kepada para pemberi data yang behubungan dengan judul yang dikembangkan oleh peneliti

3) Ucapan terimakasih kepada penerbit jurnal sehingga bisa digunakan oleh hal layak / public

\section{DAFTAR PUSTAKA}

[1] R. A.S and S. M, Rekayasa Perangkat Lunak. 2018.

[2] E. Affandi and T. Syahputra, "Pemodelan Uml Manajeman Sistem Inventory," J-SISKO TECH (Jurnal Teknol. Sist. Inf. dan Sist. Komput. TGD), 2018.

[3] M. C. Borba, P. Askar, J. Engelbrecht, G. Gadanidis, S. Llinares, and M. S. Aguilar, "Blended learning, e-learning and mobile learning in mathematics education," ZDM - Math. Educ., 2016, doi: 10.1007/s11858-016-0798-4.

[4] B. K, "Pengertian \& Konsep Dasar Machine Learning," Technosains. 2017.

[5] T. Listyorini and A. Widodo, 


\section{"PERANCANGAN MOBILE} LEARNING MATA KULIAH SISTEM OPERASI BERBASIS ANDROID," Simetris J. Tek. Mesin, Elektro dan Ilmu Komput., 2013, doi: 10.24176/simet.v3i1.85.

[6] D. S. Melyani, R. D. Angraeny, H. Sopriyadi, and A. Farisi, "Aplikasi ELearning pada Fast English Berbasis Web," Ijccs, 2015, doi: 10.2135/cropsci1983.0011183X0023 00020002x.

[7] L. F. Motiwalla, "Mobile learning: A framework and evaluation," Comput. Educ., 2007, doi:

10.1016/j.compedu.2005.10.011.

[8] H. T. Sihotang, T. Informatika, and S. Utara, "Pembuatan Aplikasi ELearning Pada Smk Swasta," J. Mantik Penusa, 2017.

[9] TATA SUTABRI, Analisis Sistem Informasi. 2012. 